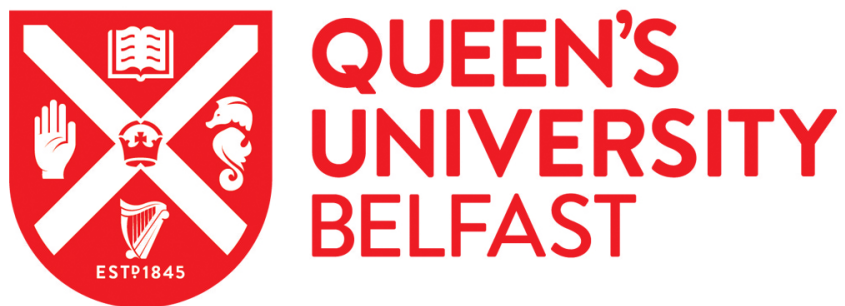

\section{Antecedents to environmental supply chain strategies: The role of internal integration and environmental learning}

Graham, S. (2018). Antecedents to environmental supply chain strategies: The role of internal integration and environmental learning. International Journal of Production Economics, 197, 283-296.

https://doi.org/10.1016/j.jpe.2018.01.005

Published in:

International Journal of Production Economics

Document Version:

Peer reviewed version

Queen's University Belfast - Research Portal:

Link to publication record in Queen's University Belfast Research Portal

Publisher rights

Copyright 2018 Elsevier

This manuscript is distributed under a Creative Commons Attribution-NonCommercial-NoDerivs License

(https://creativecommons.org/licenses/by-nc-nd/4.0/), which permits distribution and reproduction for non-commercial purposes, provided the author and source are cited.

\section{General rights}

Copyright for the publications made accessible via the Queen's University Belfast Research Portal is retained by the author(s) and / or other copyright owners and it is a condition of accessing these publications that users recognise and abide by the legal requirements associated with these rights.

Take down policy

The Research Portal is Queen's institutional repository that provides access to Queen's research output. Every effort has been made to ensure that content in the Research Portal does not infringe any person's rights, or applicable UK laws. If you discover content in the Research Portal that you believe breaches copyright or violates any law, please contact openaccess@qub.ac.uk. 


\section{Introduction}

Environmental pressures are increasing in prominence for companies across a range of different industries (Lee et al., 2015; Tognetti et al., 2015). Strategic responses to these pressures have shifted over the last three decades as companies have moved from trying to control the pollution created through their operations and supply chains in a reactive, post hoc manner, to adopt more proactive preventative approaches to dealing with pollution (Daily et al., 2012). Research in relation to this has considered the question of 'why' companies are becoming more environmentally proactive and drivers such as stakeholder and institutional pressures have been identified as important antecedents to this trend (Sarkis et al., 2010; Akin et al., 2012; Kumar et al., 2012; Hofer et al., 2012; Hoejmose et al., 2013; Grosvold et al., 2014; Gualandris et al., 2015). Studies have also sought to identify 'what' practices are being implemented within proactive companies and 'what' impact these practices are having on performance outcomes (Green et al., 2012; Graham and Potter, 2015). Empirical support for the link between environmental practices and performance has been inconclusive and recent studies have called for research to move beyond asking 'why' and 'what' questions to consider 'how' companies can implement environmental strategies more effectively (Kiron et al., 2012; Lee et al., 2015; Mejías et al., 2016). Implementation of proactive environmental strategies is a complex process that may be facilitated by a range of different factors (López-Gamero et al., 2009; De Burgos-Giminez et al., 2014). For example, the existence of complementary assets, change management practices, environmental training, top management support and employee empowerment have been highlighted as important internal factors that facilitate the implementation of environmental strategies (Christmann, 2000; Gattiker and Carter, 2010; Sarkis et al., 2010; Ronnenberg et al., 2010; Daily et al., 2012). A number of other factors may 
also support the implementation process and there is a need for research to identify and assess the influence of these factors (Zhu et al., 2012).

The natural resource-based view (NRBV) outlines three proactive environmental strategies, namely, pollution prevention, product stewardship and sustainable development (Hart, 1995; Hart and Dowell, 2011). These strategies are practically implemented through a wide range of environmental practices at the internal operations and broader supply chain levels respectively (Wong et al., 2012; Trentin et al., 2015). Research to date has predominantly focussed on identifying antecedents and performance outcomes of proactive environmental strategies (Hart and Dowell, 2011). Results in relation to performance outcomes have been somewhat ambiguous and while a positive link with environmental performance has been well supported (Vachon and Klassen, 2008; Wong et al., 2012; Tachizawa et al., 2015), the link between these strategies and other dimensions of performance remains unclear. This leads to questions about how environmental strategies can be implemented more effectively. If some companies are noting improvements across a number of performance dimensions, what are they doing differently from the ones that are not achieving the same benefits?

Few studies consider the practical implementation of proactive environmental strategies and a lesser explored proposition of the NRBV relates to the progression from implementing environmental strategies at the internal operations level to the broader supply chain level (Hart and Dowell, 2011; Zhu et al., 2012). Some studies have found support for a link between internal environmental practices and environmental practices at the supply chain level (Green et al., 2012; Zhu et al., 2012), suggesting that the implementation of internal practices is an important antecedent to supply chain practices. A key reason for this is that the capabilities, experience and learning developed through internal implementation efforts are important resources in the implementation of more advanced supply chain practices (Blome et al., 2012; Jacobs et al., 2016). A number of studies in the operations and supply chain management 
literature note the importance of internal implementation and integration of practices as an antecedent to supply chain practices (Braunschiedel and Suresh, 2009; Williams et al., 2013; Jacobs et al., 2016). These studies suggest that the implementation of certain practices internally can lead to the development of capabilities that complement or facilitate the extension of these practices to the broader supply chain level (Darnall et al., 2008; Williams et al., 2013). Hart and Dowell (2011) make a call for studies to develop understanding of key factors that support the implementation of more advanced environmental strategies. They suggest that the dynamic capabilities perspective may help with this, highlighting the importance of the integration and learning capabilities developed through internal implementation efforts in extending environmental practices to the supply chain level.

This study responds to this call by developing a theoretical model grounded in the NRBV and dynamic capabilities perspective. Data collected from the UK food industry is analysed to test the model and answer its two underpinning research questions; (1) does the implementation of an internal environmental strategy influence the level of environmental integration and development of environmental learning within companies? and; (2) do environmental integration and environmental learning mediate the relationship between internal and supply chain level environmental strategies?

This paper contributes to the environmental operations management literature (EOM) in three ways. First, it addresses the emergent and underexplored area of implementation within the EOM literature and provides empirical support for some of the conceptual arguments that have been made in this area to date. Second, it conceptualises and tests the notion that the resources and capabilities developed through the implementation of internal environmental practices are key antecedents in the extension of these practices to the supply chain level. Third, it integrates and applies the NRBV and dynamic capabilities perspectives in assessing the implementation of proactive environmental strategies. The following section presents the theoretical 
background of the study. Following this, the theoretical model and hypotheses are developed in Section 3. The research design is outlined in Section 4, followed by analysis and results in Section 5. Discussion of the results and the conclusion are presented in sections 6 and 7 respectively.

\section{Theoretical background}

Resource-based theory highlights the potential for companies to create and sustain a competitive advantage through effective management of the heterogeneous bundles of resources and capabilities that they possess (Barney, 1991; Christmann, 2000). The natural resource-based view (NRBV) and dynamic capabilities perspective are extensions of resourcebased theory that may provide insight into how companies can effectively respond to environmental pressures and challenges in a way that generates sources of competitive advantage (Hart and Dowell, 2011). This study adopts these perspectives in seeking to understand how companies implement proactive environmental strategies at the supply chain level, based on the experience gained from initial internal efforts.

The Natural Resource-Based View (NRBV)

The NRBV highlights the potential for firms to generate unique sources of competitive advantage through proactive engagement with the natural environment (Hart, 1995; Hart and Dowell, 2011). It suggests that companies can implement environmental strategies at different levels ranging from the internal operations level, to the broader supply chain level. Development and implementation of these environmental strategies follows a path-dependent progression whereby companies use the experience developed from the previous level in moving to environmental strategies at the next level (Christmann, 2000). These strategies can 
be implemented through a wide range of product or process-related environmental practices that seek to address the environmental objectives outlined in the environmental strategy (Hart, 1995; Hart and Dowell, 2011). Three key strategies are outlined within the NRBV framework. At the internal operations level a pollution prevention strategy is the first step in proactive engagement with the natural environment (Hart, 1995; Christmann, 2000). Environmental practices implemented at this level are aimed at reducing negative environmental impacts generated either by the product itself or the production process through which it is created (Schoenherr, 2012; Wong et al., 2012; Hoque and Clarke, 2013). Following the effective implementation of a pollution prevention strategy, companies may seek to extend their environmental efforts to the supply chain level through implementation of a product stewardship strategy (Hart, 1995; Hart and Dowell, 2011). This strategy is implemented through a range of environmental practices conducted at different stages of the supply chain and requires a level of engagement with key stakeholder groups such as suppliers and customers (Wong et al., 2012; Grekova et al., 2014; Mena et al., 2014). Beyond this, companies seeking to be environmental leaders within their industry can implement a sustainable development strategy (Hart, 1995). This involves extensive engagement with a wide range of stakeholders from governments to competitors in seeking to drive change at an industry level. It implies the highest level of environmental commitment and proactivity and may only be sought after by a small number of firms.

To date, empirical research has focussed predominantly on establishing the links between these strategies and various dimensions of performance. A key proposition of the NRBV is that the implementation of proactive environmental strategies can lead to sources of competitive advantage for companies (Hart, 1995; Hart and Dowell, 2011). Some empirical support has been generated for this proposition as studies have identified links with various environmental practices and different dimensions of performance (Vachon and Klassen, 2008; Schoenherr, 
2012; Graham and Potter, 2015). However, these studies often find that certain practices are positively linked to performance while others are not (Wong et al., 2012; De Burgos-Jiminez et al., 2014). Thus, the link between proactive environmental strategies and competitive advantage has obtained some support, but this has not been conclusive. One potential explanation for these mixed results is that some companies may implement environmental strategies more effectively than others and as a result achieve more positive outcomes from these strategies.

\section{The dynamic capabilities perspective}

The dynamic capabilities perspective calls attention to the need for companies to continually adapt and develop their resources and capabilities in order to sustain a competitive advantage (Teece et al., 1997; Vanpoucke et al., 2014). In dynamic markets where new opportunities and challenges continually emerge, it is not enough for companies to pursue the same rigid strategies over a long-term period as these strategies may cease to meet the needs of the market as it changes (Ambrosini and Bowman, 2009). Thus, companies must focus on the continual generation of short-term advantages through their response to emergent market conditions (Eisenhardt and Martin, 2000). The proactive environmental strategies outlined in the NRBV can be considered as dynamic capabilities that adapt and develop in response to pressures and opportunities in the external environment (Aragón-Correa and López, 2007; Hart and Dowell, 2011; Wu and Pagell, 2011). Internal processes play an important role in the development of dynamic capabilities. Three in particular have been highlighted as important, namely, integration, learning and reconfiguration (Teece et al., 1997; Ambrosini and Bowman, 2009). Integration involves the sharing of knowledge and routines across the company in order to coordinate and focus internal efforts in implementing strategic changes (Teece, 2009). Thus, if 
a company decides to pursue a proactive environmental strategy, they will need to ensure that everyone is working towards these strategic goals (Pagell and $\mathrm{Wu}, 2009$ ). To do this, they may follow a similar process to ones previously established to integrate other strategic changes or new practices. Therefore, their integration process may already be well established and they can use it to implement and support ongoing changes. Learning relates to the knowledge and experience that the company possesses. This will be unique to them, having been developed in a historical path dependent manner. Companies can draw on this knowledge and experience in implementing strategic changes associated with dynamic capabilities (Ambrosini and Bowman, 2009). For example, if a company wishes to progress from an internal environmental strategy to a supply chain environmental strategy, they will be able to draw on the experience and learning developed through their initial internal efforts (Hart, 1995). Reconfiguration involves a company adapting their existing resource and capability base in some way to meet a new or emerging need in the external environment (Teece et al., 1997). This is distinct from integration and learning in the sense that it is about responding quickly to new external challenges and opportunities as opposed to building upon and extending what has already been done in relation to existing opportunities and challenges. The focus of this paper is on proactive environmental strategies which are implemented in response to a range of pre-existing external pressures. While, these pressures have grown in force in recent years (Lee et al., 2015; Tognetti et al., 2015), their goal to encourage companies to reduce negative environmental impacts remains the same. Therefore, it is of interest to consider how companies progressively develop their environmental capabilities in response to these pressures considering the concepts of integration and learning as supporting factors. 


\section{Theoretical Framework and Hypothesis Development}

A theoretical framework grounded in the NRBV and dynamic capabilities perspective has been developed for this study (see Figure 1). There are two key aspects to the framework. Firstly, the implementation of an internal, pollution prevention strategy is considered as an antecedent to the development of environmental integration and learning capabilities. This is consistent with the arguments of the NRBV suggesting that the implementation of internal environmental strategies and practices generates resources and capabilities that are vital to the implementation of more advanced environmental strategies at the supply chain level (Hart, 1995; Hart and Dowell, 2011). While some studies provide empirical support for the suggested link between internal and supply chain level practices (Green et al., 2012; Grekova et al., 2014), fewer consider the underlying reason for this link, namely, the generation of facilitative resources and capabilities through internal efforts (Bowen et al., 2001; Hart and Dowell, 2011). The second key aspect of the framework builds on this further by considering the mediating effects of integration and learning on the progression from pollution prevention to process stewardship. This is in accordance with the more recently developed arguments of the NRBV that promote consideration of proactive environmental strategies as dynamic capabilities requiring support from internal processes in their implementation (Hart and Dowell, 2011). The dynamic capabilities perspective suggests that integration and learning capabilities are important antecedents to the development of more advanced strategies and practices (Ambrosini and Bowman, 2009). These arguments from both perspectives underpin the mediation hypotheses in the model. The following sections discuss each of the constructs comprising the framework and their hypothesised interactions with each other. 


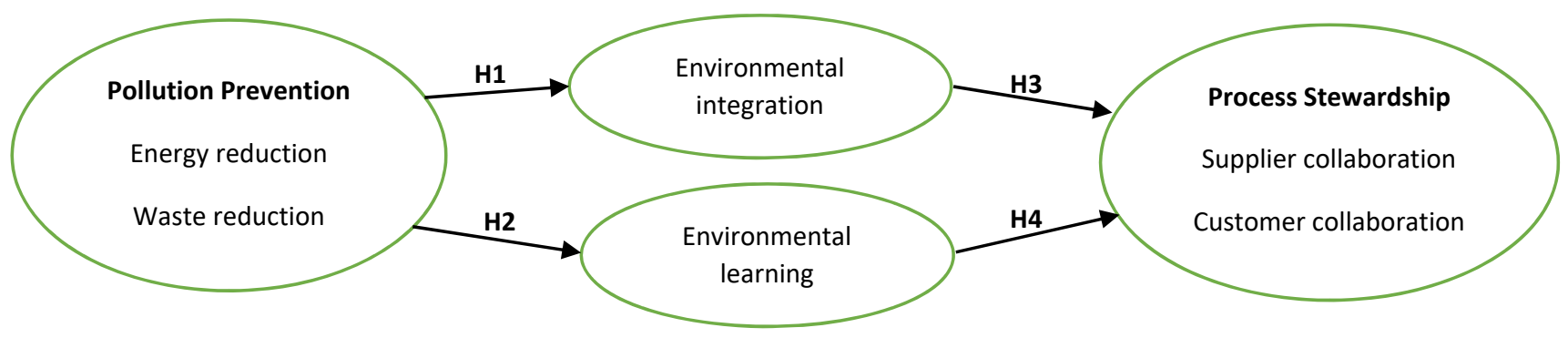

Figure 1

\section{Pollution Prevention}

Pollution prevention constitutes the first proactive environmental strategy outlined in the NRBV (Hart, 1995; Hart and Dowell, 2011). It targets focus on the reduction of environmental impacts at the internal operations level of the firm and can be practically implemented through a range of practices designed to reduce these impacts within the production process (Trentin et al., 2015). A key objective of pollution prevention is to eliminate pollution at its source in the production process (Thoumy and Vachon, 2012; Hoque and Clarke, 2013). This requires product or process modifications that reduce the levels of pollution generated throughout production (Schoenherr, 2012). The implementation of pollution prevention takes place at both the tactical and strategic level. At the tactical level, product or process specific changes might be applied in order to minimise the level of pollution generated by the operation (Klassen, 2000). This may be further supported by infrastructural investment in management systems at a more strategic level leading to formalised procedures and employee training on environmental practices, thus, encouraging employee engagement with pollution prevention efforts (Klassen, 2000; Thoumy and Vachon, 2012). Thus, the practical implementation of a pollution prevention approach requires pre-planned and coordinated efforts to prevent pollution at its source. The preventative nature of pollution prevention suggests that companies adopting 
this approach are proactive in their response to environmental concerns and challenges (Buysse and Verbeke, 2003; Gonzalez-Benito and Gonzalez-Benito, 2005; Murillo-Luna et al., 2011).

In contrast, companies adopting a more reactive environmental response tend to deal with pollution concerns in a post-hoc manner when certain pollution targets have been overstepped and they are required to take action (Buysse and Verbeke, 2003; Munguia et al., 2010). This end-of-pipe pollution control approach is the antithesis to pollution prevention as adopters seek to maintain acceptable levels of pollution and avoid fines or penalties associated with exceeding these levels as opposed to redesigning systems and practices in order to prevent the occurrence of pollution in the first place (Munguia et al., 2010; Belayuthum et al., 2016). Thus, implementation occurs at the end of the process and problems are dealt with using a fire fighting approach (Walley and Whitehead, 1994). Environmental efforts are not pre-planned and coordinated as they are in the pollution prevention approach suggesting that environmental concerns are not held in high regard by companies adopting this response. Thus, there are notable differences in the levels of implementation of proactive pollution prevention approaches and reactive pollution control approaches as well as the stages in the process at which they are implemented (Hart, 1995; Buysse and Verbeke, 2003; Murillo-Luna et al., 2011; Graham and Potter, 2015).

A pollution prevention strategy will be implemented in heterogeneous ways within different companies as specific pollution-related challenges may vary across industry and sub-industry groups. This makes it difficult to prescribe specific practices for companies to adopt in relation to pollution prevention and studies have operationalised the concept in different ways (AbouElela et al., 2008; Schoenherr, 2012; Hoque and Clarke, 2013). A general emphasis on the reduction of energy and waste is evident in the implementation of pollution prevention (Hart, 1995; Montabon et al., 2007; Michalisin and Stinchfield, 2010; Tate et al., 2010). Thus, for the 
purpose of this study, the concept of pollution prevention has been broken down into two sets of practices, namely, energy consumption reduction and waste reduction.

Energy and waste reduction are important areas of focus for environmental efforts across a number of industries (Tate et al., 2010). Within the UK food industry concerns have been raised over the level of carbon emissions and waste generated in food production and targets have been set to encourage food producing companies to tackle these areas (Environment Agency, 2012; FDF, 2017; DEFRA, 2017). Excessive levels of energy use and waste may be indicative of inefficiencies in the production process (Bansal and McKnight, 2009). The majority of companies within the food industry compete on cost and face unique challenges in relation to timing and perishability of products (Mattas and Tsakiridou, 2010; Darkow et al., 2015; New, 2015). Thus, efficiency is important to companies within this industry for reasons beyond addressing environmental concerns. As energy and waste present key pollution challenges within the food industry context (Maloni and Brown, 2006; Pullman et al., 2009), it is appropriate to consider practices aimed at their reduction as comprising efforts to prevent pollution within the production process.

Pollution prevention is one of the most commonly implemented environmental strategies in industry (Schoenherr, 2012; Thoumy and Vachon, 2012). While studies have considered different antecedents and outcomes of pollution prevention (Klassen, 2000; Abou-Elela et al., 2008; Schoenherr, 2012; Hoque and Clarke, 2013; Graham and Potter, 2015), no previous studies appear to consider its influence in the implementation of environmental strategies at the supply chain level as suggested in the NRBV. Thus, this study addresses an important research gap in doing so. 


\section{Process Stewardship}

Implementation of a stewardship strategy reflects environmental efforts being conducted beyond the internal boundaries of the firm at the broader supply chain level. Hart (1995) labels this next level of environmental strategy 'product' stewardship, emphasising its focus on reducing environmental impacts generated by products at different stages of their life cycle. Life cycle analysis techniques seek to measure and reduce the environmental impact of a product at different stages of its life cycle from product design through to end-of-life and disposal (Bhupendra and Sangle, 2016). Practical application of this approach may involve working with suppliers to design more environmentally friendly products with consideration of environmental impact during product use and disposal (Hart, 1995; Hart and Dowell, 2011). A number of companies design their products with consideration of life cycle environmental impact effects. For example, in the automotive industry, manufacturers are under increasing pressure to reduce the emissions generated during the product use stage as well as increase the recyclability of components at the end of life stage (Hawkins et al., 2013).

Recent studies suggest that the principles of life cycle analysis can be extended beyond product design to measure and reduce the environmental impact of different stages of the production process (Wong et al., 2012; Graham and Potter, 2015). 'Process' stewardship is similar to product stewardship in that it addresses environmental impact at the supply chain level, yet distinct, in that its focus is process-based as opposed to product-based. This distinction is reflected in the literature as studies have often focused on either product-based environmental practices (Sarkis et al., 2010), or process-based environmental practices (Vachon and Klassen, 2008; Lee, 2015; Tognetti et al., 2015). The focus on process-based environmental practices appears to be more prominent. A reason for this may be that pressure to reduce process-related carbon emissions and pollution affects all manufacturing companies (Lee et al., 2015), 
whereas, not all types of product will lend themselves to product-based practices such as ecodesign. Within the context of the food industry, the supply chain processes as opposed to the products themselves, generate the highest level of environmental impact (Pullman et al., 2009; Agustina et al., 2014). For this reason, process stewardship is the concept adopted in this study.

A process stewardship strategy can be practically implemented through a range of environmental practices at different stages of the supply chain (Hart and Dowell, 2011; Wong et al., 2012; Graham and Potter, 2015). Monitoring and collaboration with suppliers and customers represent key process-based environmental supply chain practices (Vachon and Klassen, 2008; Lee, 2015; Formentini and Taticchi, 2016). These practices express a company's efforts to engage with other companies in assessing and improving their environmental impact at the supply chain level. Monitoring practices involve gathering information in order to assess the environmental performance of suppliers (Lee, 2015; Marshall et al., 2015). This is often led by the focal company who collect and process the information, with minimal input or engagement with the suppliers being assessed (Vachon and Klassen, 2006). These practices are becoming more prominent as companies are increasingly expected to monitor the environmental impact of their supply chain processes (Lee et al., 2015).

Collaborative practices imply a high level of engagement between supply chain companies such as, customers and suppliers (Blome et al., 2014; Grekova et al., 2014; Lee, 2015). These practices are typically more supportive than monitoring practices and can lead to improved supply chain relationships (Vachon and Klassen, 2008; Grimm et al., 2014). Collaboration involves a joint effort to improving environmental performance at the supply chain level whereby input is sought from suppliers and customers (Vachon and Klassen, 2008; Giminez and Sierra, 2013). This is a complex environmental practice, requiring a high level of 
proactivity and commitment from the focal company (Vachon et al., 2009; Wiengarten et al., 2011; Graham and Potter, 2015; Formentini and Taticchi, 2016).

The use of monitoring or collaboration as governance mechanisms for the implementation of environmental practices at the supply chain level may be linked to the relative power of different actors within the supply chain (Formentini and Taticchi, 2016). The issue of power balance in supply chain relationships is an important consideration in the implementation of collaborative practices (Hingley, 2005). Supply chain relationships within the UK food industry are dominated by powerful retailers downstream in the supply chain resulting in significant power imbalance within these particular supply chains (Hingley, 2005; Hingley et al., 2015). In spite of this, research suggests that retailers increasingly seek closer relationships with fewer suppliers because they perceive there to be benefits associated with working more closely with their supply chain partners (Hingley, 2005). Further, retailers may be the ones held to account for environmental impacts generated within their supply chains because of stakeholder perceptions of the power and influence they hold. Thus, it might be in their best interest to implement collaborative environmental practices with suppliers that reduce the overall environmental impact of their supply chains (Giminez and Sierra, 2013).

For the purpose of this study, collaborative supply chain practices are considered more consistent with the proactive nature of process stewardship than monitoring practices. Engagement with key stakeholders plays an important role in extending environmental practices to the supply chain level (Hart, 1995; Hart and Dowell, 2011). Suppliers and customers are key stakeholder groups within the supply chain process so the concept of collaboration with these parties captures the engagement inherent in the practical implementation of a process stewardship strategy (Vachon and Klassen, 2008; Hart and 
Dowell, 2011). In contrast, supply chain monitoring is more consistent with a reactive approach whereby companies monitor the activities of suppliers in response to pressures to measure the environmental impact of their supply chain (Gualandris et al., 2015; Lee et al., 2015).

Within the UK food industry, companies are being pressured to consider the environmental impact of their supply chains (FDF, 2017; DEFRA, 2017). Different environmental challenges will face companies at different stages of the food supply chain. For example, wasteful water consumption, soil erosion and degradation and pollution from pesticides are key environmental challenges for companies upstream in the supply chain involved with farming and agriculture (Pullman et al., 2009). Energy use and waste are key challenges for companies involved with food processing and pollution from transportation and packaging waste are key issues for companies downstream in the food supply chain (Preuss, 2005; Shukla and Jharkharia, 2013; FDF, 2017). Monitoring practices can be used to measure some of these impacts and communicate improvement targets to key stakeholders. Companies in the UK food industry are already required to monitor the production of food products throughout the supply chain closely and ensure traceability within the overall process (Roth et al., 2008). Therefore, companies in this industry already have systems in place to monitor supplier processes and can develop these further to incorporate environmental impacts into these systems. Collaboration practices go further than this to promote a joint effort towards tackling environmental concerns that enables higher levels of improvement to be obtained throughout the supply chain (Vachon and Klassen, 2008).

The relationship between Pollution Prevention and Process Stewardship 
The NRBV suggests that the implementation of proactive environmental strategies within companies should take place in stages, starting with internally focussed environmental strategies (pollution prevention) before progressing to more advanced environmental strategies implemented at the supply chain level (process stewardship) (Hart, 1995; Hart and Dowell, 2011; Grekova et al., 2014). Consistent with this, empirical support has been generated to confirm the important role of internal environmental practices as antecedents to more advanced practices implemented at the supply chain level (Testa and Iraldo, 2010; Arimura et al., 2011; Green et al., 2012; Zhu et al., 2012; Grekova et al., 2014; Trentin et al., 2015). A key reason for this is that the implementation of internal practices leads to the development of capabilities that are conducive to the implementation of more advanced practices (Darnall et al., 2008; De Giovanni, 2010; Trentin et al., 2015; Jacobs et al., 2016). Darnall et al. (2008) demonstrate this in their study on the relationship between quality management systems and the implementation of environmental management standards, highlighting that complementary capabilities developed through the former contribute to implementation of the latter. Thus, they suggest that capabilities developed through existing practices can complement the implementation of more advanced practices. Hart and Dowell (2011) call for more studies to consider the role of complementary capabilities in progressing towards more advanced environmental practices. In this regard, environmental strategies can be considered as dynamic capabilities that companies seek to develop and extend over time as they develop the capabilities needed to move towards more advanced strategies (Aragón-Correa and López, 2007; Hart and Dowell, 2011). The dynamic capabilities perspective highlights integration and learning as complementary capabilities that support the development of more advanced strategies or practices (Schreyogg and Kliesch-Eberl, 2007; Ambrosini and Bowman, 2009; Teece, 2009). 
The concept of integration has been extensively explored within the general supply chain management literature (Gimenez et al., 2012; Huo, 2012; Schoenherr and Swink, 2012; Zsidisin et al., 2015). Research interest in this concept can be linked back to a seminal article by Frohlich and Westbrook (2001) which highlights the potential for higher levels of integration to influence organisational performance. While definitional and conceptual ambiguity exist, a general distinction between internal and external forms of integration is highlighted in a number of studies (Braunschiedel and Suresh, 2009; Gimenez et al., 2012; Schoenherr and Swink, 2012; Turkulainen and Ketokivi, 2012). Internal integration involves interaction, coordination and collaboration among the different functions within an organisation to facilitate a combined effort in achieving organisational goals (Pagell, 2004; Schreyogg and Kliesch-Eberl, 2007; Schoenherr and Swink, 2012; Zsidisin et al., 2015). External integration involves the extension of interaction, coordination and collaboration efforts to the supply chain level with suppliers and customers (Flynn et al., 2010; Schoenherr and Swink, 2012). This study adopts the internal conceptualisation defining environmental integration as the integration of environmental objectives and efforts throughout the organisation (Pagell and $\mathrm{Wu}, 2009$ ). Internal integration can be viewed as an important prerequisite to external integration (Zsidisn et al., 2015). Thus, companies should seek to attain a level of internal environmental integration before pursuing integration at the supply chain level (Jacobs et al., 2016).

As companies implement new environmental strategies or practices, they will go through a process of learning (Hart, 1995; Hart and Dowell, 2011). The learning process that takes place throughout the implementation of new systems or practices leads to the generation of tacit knowledge capabilities which may be of value in the implementation of other, related practices or systems (Darnall et al., 2008; Zhu et al., 2008). These learning capabilities are a valuable resource in the development of more advanced strategies and practices, yet their effectiveness 
can be restricted if internal structures to enable adoption of any knowledge are not in place (Pil and Rothenberg, 2003; Darnall et al., 2008; Tashman and Marano, 2009). Learning capabilities will be unique and idiosyncratic to individual companies and each will go through this process differently. As internal environmental strategies such as pollution prevention are implemented, employees at different levels of the organisation will start to develop tacit knowledge about the best way of dealing with certain issues or challenges (Hart, 1995; Hart and Dowell, 2011). As they continue to implement such strategies, their environmental capabilities should be improved through this learning as they identify what works well and what doesn't.

The implementation of a pollution prevention strategy should generate higher levels of internal environmental integration and learning as employees are encouraged to engage with practices aimed at reducing pollution (Hart, 1995; Pagell and $\mathrm{Wu}, 2009$ ). Pollution prevention requires a continuous improvement approach whereby all employees are encouraged to identify and engage with efforts to reduce energy emissions and waste levels (Hart, 1995; Hart and Dowell, 2011; Wong et al., 2012). Thus, consistent with the arguments of the NRBV and implicit assumption inherent in other studies that the implementation of internal environmental strategies leads to the development of integration and learning capabilities (Darnall et al., 2008; Jacobs et al., 2016), the following hypotheses are developed;

H1: The implementation of pollution prevention has a direct and positive influence on the development of environmental integration capabilities.

H2: The implementation of pollution prevention has a direct and positive influence on the development of environmental learning capabilities. 
Hart and Dowell (2011) call for studies to consider the role of integration and learning capabilities developed through the implementation of internal environmental strategies in progressing towards more advanced environmental strategies at the supply chain level. An implicit assumption of the NRBV is that companies need to develop such capabilities through internal environmental efforts before extending these efforts to the supply chain level (Hart, 1995; Hart and Dowell, 2011). A number of studies consider the relationship between internal practices and supply chain practices to be direct, providing support for the antecedent role played by internal practices in the development of more advanced practices (De Giovanni, 2010; Green et al., 2012). Recent studies highlight the importance of understanding key mediating and moderating factors that might influence the effectiveness of environmental practice implementation (Gallear et al., 2014; Marshall et al., 2015; Jacobs et al., 2016). The dynamic capabilities perspective suggests that integration and learning support the implementation of more advanced capabilities and practices (Schreyogg and Kliesch-Eberl, 2007). Applying this logic to the context of environmental capabilities and practices, it could be suggested that the internal integration of environmental efforts and the learning generated through these efforts are important antecedents to the implementation of more advanced environmental practices at the supply chain level (Hart and Dowell, 2011). Thus, it is not just the existence of internal environmental practices that precedes the implementation of more advanced practices. Rather, the integration and learning capabilities developed through internal efforts mediate the implementation of efforts at the supply chain level. A number of studies highlight the importance of integration and learning in progressing towards more advanced environmental practices without explicitly testing for mediating effects (King and Lennox, 2001; Pil and Rothenberg, 2003; Darnall et al., 2008; Zhu et al., 2008; Daily et al., 2012; De Giovanni, 2012; Grekova et al., 2014). Some recent studies highlight the potential for capabilities developed through internal environmental efforts to mediate the progression 
towards more advanced practices (Gallear et al., 2014; Jacobs et al., 2016). Consistent with these studies and the arguments of the NRBV and dynamic capabilities perspective, the following hypotheses are developed;

H3: The relationship between pollution prevention and process stewardship is mediated by environmental integration capabilities.

H4: The relationship between pollution prevention and process stewardship is mediated by environmental learning capabilities.

\section{Research Design}

Research Context

The food industry faces a broad and unique set of environmental challenges ranging from the environmental impact of pesticide use upstream in the supply chain to the pollution generated through transportation and logistics processes downstream in the supply chain (Maloni and Brown, 2006; Pullman et al., 2009; Mattas and Tsakiridou, 2010; Yu and Nagurney, 2013; New, 2015). In some respects, environmental pressures within this industry could be considered more complex than other industries as the issue of time can create problems, especially in the production of perishable food items (Bourlakis and Weightman, 2004; Roth et al., 2008; Shukla and Jharkharia, 2013). Reduction of carbon emissions and waste are key challenges for the food industry as pressures to address environmental impacts throughout the food supply chain have increased in recent years (FDF, 2017; DEFRA, 2017). In light of the complexity of environmental challenges facing this industry, recent calls have been made for 
studies to consider the implementation of environmental practices within this context (Darkow et al., 2015). Further, as the largest manufacturing sector in many developed and developing countries, it is an important context for studies to consider (Accorsi et al., 2014; Agustina et al., 2014; Li et al., 2014). The single-industry focus adopted in this study enables examination of the context-specific practices adopted and facilitates the generalisation of results across food manufacturing companies (Darkow et al., 2015; New, 2015). Moreover, focus on the UK as the national context for the study removes the potential for differing regulations to influence results (Pagell and Gobeli, 2009; Sarkis et al., 2010; Marshall et al., 2015).

The UK food industry is dominated by a small number of large retailers who exert strong influence on the shape and design of food supply chains within the UK (Hingley, 2005). Retailers such as Tesco, Sainsbury and Asda are seeking to obtain greater control and transparency across all stages of the various supply chains of the products they stock and sell (Hingley, 2008). This has led to a shift towards the development of closer relationships with a smaller number of suppliers (Hingley et al., 2015). However, from the suppliers' perspective, these relationships may not always appear to be mutually beneficial due to a power imbalance in favour of the large retailers (Hingley et al., 2015). As environmental concerns are increasingly pushed up the agenda of large UK retailers it is of interest to consider the practical response to some of these issues within their supply chains, from the suppliers' perspective (SBM, 2010; Smithers, 2012). A significant amount of the environmental impact generated within food supply chains occurs at the manufacturing or processing stage (Pullman et al., 2009). Thus, food manufacturing companies are the key point of contact for the data collection for this study. 


\section{Sample and Data Collection}

The first stage of the research design involved the collection of qualitative data through a series of semi-structured interviews. This stage was conducted for the purpose of developing the survey instrument used to collect data at the next stage. Due to the process-level focus of the study, production and operations managers were targeted as interviewees. A total of five semistructured interviews were conducted with managers from a range of different sub-industries, namely, red meat, prepared vegetables, poultry, bakery and potatoes. A range of environmental challenges, pressures, experiences and practices specific to the food industry context were highlighted at this stage. The qualitative findings were corroborated with secondary data from online sources such as the Food and Drink Federation (FDF) and the Department for Environment, Food and Rural Affairs (DEFRA), as well as literature on environmental issues in the food industry (Maloni and Brown, 2006; Pullman et al., 2009). The qualitative data collected at this stage confirmed the existence of some of the key environmental practices identified through the literature review within the food industry context. All interviewees talked about energy and waste reduction as key challenges within this context as well as pressures to extend environmental efforts to the supply chain level. It was also evident that companies adopt different approaches in responding to these challenges. For example, in some cases energy consumption reduction efforts involved companywide frugality with energy consumption through machinery, lighting and computers. In other cases, investments in energy efficient machinery or even incineration systems whereby energy can be generated through waste products had been implemented. Due to the heterogeneity in practice implementation within this context, the measures were designed to capture the existence of environmental practices such as energy and waste reduction in a general way, rather than specifying prescribed ways in which companies might attain these practices. Taken together, this data was used in developing 
the survey instrument which was pilot tested with a further six managers and six senior academics to ensure quality (Drucker, 2005).

The survey was then sent to a sample of 1200 manufacturing companies based in the UK. The sample included medium (50-249 employees) and large ( $>250$ employees) companies, as some studies suggest that environmental pressures and responses may be greater in these companies than smaller companies (Awaysheh and Klassen, 2010; Darnall et al., 2010). Standard Industrial Classification (SIC) DA 15, which includes a number of sub-industries such as meat, dairy, animal feed, grain, starch, fruit and vegetables, was also used as a criterion for defining the final sample. This ensured that a good range of food companies were included and enabled a comprehensive assessment of the key environmental issues within this industry. Production and operations managers were targeted as key informants, consistent with the process-level focus of the study. The distribution of the survey adhered to Dillman's (2007) tailored design method and follow-up phone calls were used to encourage further responses (Forza, 2002). A total of 149 responses were obtained following three mailings of the survey. This $12.4 \%$ response rate is consistent with other cross-sectional survey studies in the area (e.g. Paulraj, 2011; Marshall et al., 2015). Non-response bias was assessed through a comparison of early and late responses under the assumption that late respondents possess similar characteristics to non-respondents (Armstrong and Overton, 1977; Foerstl et al., 2013). Further $t$-tests were conducted on key variables to assess for significant differences. No significant differences were identified in these analyses, suggesting that non-response bias does not pose a concern for the data.

\section{Measures}


The constructs outlined in the theoretical framework were operationalised through the development of a number of new measures. Where possible, existing measures were used but due to the emergent nature of this research area, this was not possible for most of the constructs. To ensure content validity, all new measures were grounded strongly in the existing literature (Chen and Paulraj, 2004). Further, insight was drawn from the qualitative findings obtained through preliminary interviews and established guidelines for scale development were followed throughout this process (Hair et al., 2006). Validity was further ensured through the use of multiple indicators for each construct. Responses were anchored from either "strongly agree" to "strongly disagree" or "not at all" to "a very great extent" using a seven point Likert scale.

\section{Independent variables}

Operationalization of the independent variables comprising the concept of pollution prevention required the development of two new scales, namely, energy consumption reduction and waste reduction. These scales were informed by the literature on pollution prevention as well as studies based in the food industry context (Hart, 1995; Klassen, 2000; Pullman et al., 2009; Schoenherr, 2012). Further insight was drawn from online resources such as DEFRA and FDF which facilitated understanding of pollution related challenges within the food industry. Again, the qualitative findings from the first stage of data collection were also drawn upon in the development of these new measures. A five item scale was used to assess energy consumption reduction and a six item scale was used to measure waste reduction.

\section{Mediating variables}


New measures were also developed for the two mediating variables outlined in the framework, namely, integration and learning. The items comprising these scales were informed by the literature on dynamic capabilities (Schreyogg and Kliesch-Eberl, 2007; Tashman and Marano, 2007; Ambrosini and Bowman, 2009), as well as definitions from studies that have considered either integration or learning as key concepts (e.g. Chen and Paulraj, 2004). Further insight was drawn from studies encouraging the application of these concepts in the context of environmental management (Pagell and Wu, 2009; Hart and Dowell, 2011). A three-item scale was used to measure the level of environmental integration and a four-item scale to measure learning from previous environmental efforts. These variables are assessed as dependent variables ( $\mathrm{H} 1$ and $\mathrm{H} 2)$, and mediating variables ( $\mathrm{H} 3$ and $\mathrm{H} 4)$.

\section{Dependent variables}

The dependent variables comprising the concept of process stewardship were supplier collaboration and customer collaboration. These scales were adapted from Paulraj (2008) and Vachon and Klassen (2008). Four items were used to assess supplier collaboration and five items to assess customer collaboration. These measures were considered appropriate to capture the overall construct of process stewardship outlined in the NRBV (Hart, 1995; Hart and Dowell, 2011) as they reflect proactive environmental practices being implemented at the supply chain level.

\section{Exploratory Factor Analysis}

In order to test the effectiveness of the scales as measures of their overall constructs, exploratory factor analysis (EFA) was used (Hair et al., 2006). In conjunction with this, 
Bartlett's test for spherecity as well as Kaiser Meyer Olkin's (KMO) test were also examined to assess the strength and significance of relationships among the items within each construct (Vogt, 2005). The six scales were rotated in two sets of three (see Appendix Tables 1a and 1b). In both factor rotations the KMO scores were above 0.8 with highly significant Bartlett's test of sphericity figures $(p<.001)$, suggesting that the items were suitable for factor analysis. Convergence validity was assessed through examination of the standardised loadings, all but one of which were statistically significant and above the .60 threshold providing support for the validity of the measures (Hair et al., 2006). The only loading below the threshold was very close at .59 and was not deemed a cause for concern. Further, no cross-loading factors above 0.4 were identified, providing support for discriminant validity. In the first factor analysis, a three factor solution was suggested with eignenvalues above 1 and a high level of variance explained $(>80 \%)$. The second factor analysis also suggested a three factor solution with eigenvalues above 1 and a high level of variance explained (>75\%). This analysis indicates that the six scales used to measure the constructs outlined in the theoretical framework are valid measures. This was further confirmed through inspection of scree-plot diagrams. Further analysis considered the Cronbach Alpha scores of each of the scales which ranged from 0.85 to 0.94 indicating a high level of measurement reliability (Hair et al., 2006).

\section{Analysis and results}

The hypotheses were tested using hierarchical regression analysis. This technique assesses the combined effect of a set of independent variables on an outcome, whilst accounting for the variance explained by a set of controls (Hair et al., 2006; Greene, 2011). Prior to analysis, all independent variables were mean-centred to avoid the problem of multicollinearity. Variance inflation factor (VIF) and tolerance values were also examined to assess for multicollinearity. 
All values fell within the recommended intervals suggesting that multicollinearity is not a concern for the data. In addition to this, a series of residual diagnostic tests, univariate and graphical analyses were conducted to ensure the assumptions for regression analysis were met (Hair et al., 2006). These tests further confirmed the suitability of the data for analysis (Field, 2009; Greene, 2011). A series of regression models were run to test the hypotheses. Each model contained three steps; (1) inclusion of five control variables to control for organisational characteristics that might influence results: firm size (i.e. the natural logarithm of the number of employees) and four sub-industry variables, namely, processed food, beverage, meat and dairy (i.e. dichotomous variables indicating the sub-industry group from which the firm derives based on four-digit SIC codes); (2) regression of the independent variable on the outcome variable; (3) inclusion of the mediating variable to assess its effect on the relationship between the independent and outcome variables. Results for direct effects in relation to pollution prevention and environmental capabilities are outlined in Table 1. Results for direct and mediating effects in relation to energy consumption reduction and the two process stewardship practices are outlined in Table 2. Results for these effects in the cases where waste reduction constitutes the independent variable are displayed in Table 3 . In order to assess the influence of each mediator on the relationship between the independent variables and the outcome variables, two separate regression models were run for each independent variable and each outcome. This involved changing the mediator at step 3 of the model, while keeping the variables in steps 1 and 2 the same. Thus, the results for the different mediators are presented as step 3 (a) and step 3 (b) in the results tables and the results from the first two steps are not replicated.

\section{Hypothesis testing}


The first regression models assess the direct effects of pollution prevention (energy and waste reduction) on the development of environmental capabilities (integration and learning) in accordance with hypotheses 1 and 2 . To assess the overall significance of each model, attention was paid to the $R^{2}$ and $F$ statistic as well as the coefficient of the independent variable. In all of the regression models, these statistics supported overall model significance. Environmental integration constitutes the outcome variable in the first regression model and environmental learning constitutes the outcome in the second (see Table 1). The first step in each of these models indicates that the control variables explain a small proportion of the variance in the outcome variables, 15 percent $\left(R^{2}=.15\right)$ in the case of environmental integration and 16 percent $\left(R^{2}=.16\right)$ in the case of environmental learning. Inclusion of the independent variables, energy and waste reduction, at step two generates an increase in the level of variance explained in the outcome to, 54 percent $\left(R^{2}=.54 ; \mathrm{p}<0.001\right)$ in the case of environmental integration and 50 percent $\left(R^{2}=.50 ; \mathrm{p}<0.001\right)$ in the case of environmental learning. Considered in conjunction with the highly significant correlation coefficients for energy consumption reduction and waste reduction in each model, these results provide strong support for hypotheses 1 and 2. 
Table 1 Pollution prevention to environmental capabilities. Direct effects.

\begin{tabular}{|c|c|c|c|c|}
\hline & \multicolumn{2}{|c|}{$\begin{array}{l}\text { ENVIRONMENTAL } \\
\text { INTEGRATION }\end{array}$} & \multicolumn{2}{|c|}{$\begin{array}{c}\text { ENVIRONMENTAL } \\
\text { LEARNING }\end{array}$} \\
\hline & STEP 1 & STEP 2 & STEP 1 & STEP 2 \\
\hline \multicolumn{5}{|l|}{ Control Variables: } \\
\hline Firm Size & $.38 * * *$ & $.19 * *$ & $.39 * * *$ & $.21 * * *$ \\
\hline Process Food Industry & -.01 & -.11 & .04 & -.06 \\
\hline Beverage Industry & -.07 & -.15 & .08 & .00 \\
\hline Meat industry & -.04 & -.01 & .03 & .06 \\
\hline Dairy Industry & .04 & .01 & .09 & .05 \\
\hline \multicolumn{5}{|l|}{ Direct Effects: } \\
\hline Energy consumption reduction Practices & & $.52 * * *$ & & $.45^{* * *}$ \\
\hline Waste Reduction Practices & & $.18 * *$ & & $.22 * *$ \\
\hline (Constant) & $1.97 * * *$ & $1.12 *$ & $1.60 * * *$ & $1.13 *$ \\
\hline$\Delta \mathrm{R}^{2}$ & .15 & .38 & .16 & .38 \\
\hline$\Delta \mathrm{F}$ & $5.18 * * *$ & $57.64 * * *$ & $5.37 * * *$ & $46.82 * * *$ \\
\hline Overall $\mathrm{R}^{2}$ & .15 & .54 & .16 & .50 \\
\hline Adjusted $\mathrm{R}^{2}$ & .12 & .51 & .13 & .47 \\
\hline Overall model F & $5.18 * * *$ & $23.12 * * *$ & $5.37 * * *$ & $19.69 * * *$ \\
\hline $\mathrm{N}$ & 149 & 149 & 149 & 149 \\
\hline
\end{tabular}

Note: $* * * \mathrm{p}<0.001,{ }^{* *} \mathrm{p}<.05,{ }^{*} \mathrm{p}<.10$ (one-tailed tests for hypotheses; two-tailed tests for controls). Standardized regression coefficients are shown. 
Table 2- Results for direct and mediating effects of energy consumption reduction on process stewardship

\begin{tabular}{|c|c|c|c|c|c|c|c|c|}
\hline & \multicolumn{4}{|c|}{ SUPPLIER COLLABORATION } & \multicolumn{4}{|c|}{ CUSTOMER COLLABORATION } \\
\hline & STEP 1 & STEP 2 & STEP 3 (A) & STEP 3 (B) & STEP 1 & STEP 2 & STEP 3 (A) & STEP 3 (B) \\
\hline Control Variables: & & & & & & & & \\
\hline Firm Size & .02 & -.09 & $-.17 *$ & $-.20 *$ & $.16^{*}$ & .04 & -.07 & -.10 \\
\hline Process Food Industry & -.05 & -.11 & -.07 & -.09 & .01 & -.05 & .01 & -.02 \\
\hline Beverage Industry & -.09 & -.16 & -.10 & $-.15^{\wedge}$ & -.10 & $-.17 *$ & -.07 & -.16 \\
\hline Meat Industry & -.03 & -.02 & -.01 & -.04 & -.11 & -.09 & -.08 & -.12 \\
\hline Dairy Industry & -.02 & -.03 & -.05 & -.07 & .05 & .03 & .01 & -.03 \\
\hline Direct Effects: & & & & & & & & \\
\hline Energy consumption reduction & & $.42 * * *$ & .17 & .14 & & $.43 * * *$ & .07 & .07 \\
\hline Mediating Effects: & & & & & & & & \\
\hline Environmental Integration & & & $.38 * * *$ & & & & $.57 * * *$ & \\
\hline Environmental Learning & & & & $.46 * * *$ & & & & $.62 * * *$ \\
\hline (Constant) & $4.14 * * *$ & $4.88 * * *$ & $5.26 * * *$ & $5.51 * * *$ & $2.68 * * *$ & $3.48 * * *$ & $4.07 * * *$ & $4.37 * * *$ \\
\hline$\Delta \mathrm{R}^{2}$ & .01 & .16 & .07 & .11 & .06 & .17 & .15 & .20 \\
\hline$\Delta \mathrm{F}$ & .23 & $26.34 * * *$ & $12.84 * * *$ & $21.18 * * *$ & 1.67 & $30.56 * * *$ & $34.03 * * * *$ & $48.06^{* * *}$ \\
\hline Overall $\mathrm{R}^{2}$ & .01 & .16 & .23 & .27 & .06 & .22 & .37 & .42 \\
\hline Adjusted $\mathrm{R}^{2}$ & -.03 & .13 & .20 & .24 & .02 & .19 & .34 & .39 \\
\hline Overall model F & .23 & $4.62 * * *$ & $6.12 * * *$ & $7.54 * * *$ & 1.67 & $6.78 * * *$ & $12.02 * * *$ & $14.60 * * *$ \\
\hline $\mathrm{N}$ & 149 & 149 & 149 & 149 & 149 & 149 & 149 & 149 \\
\hline
\end{tabular}

Note. ${ }^{* * *} \mathrm{p}<0.001,{ }^{* *} \mathrm{p}<.05,{ }^{*} \mathrm{p}<.10,{ }^{\wedge} \mathrm{p}<.10$ (one-tailed tests for hypotheses; two-tailed tests for controls; standard errors in parenthesis). Standardized regression coefficients are shown. 
Table 3- Results for direct and mediating effects of waste reduction on process stewardship

\begin{tabular}{|c|c|c|c|c|c|c|c|c|}
\hline & \multicolumn{4}{|c|}{ SUPPLIER COLLABORATION } & \multicolumn{4}{|c|}{ CUSTOMER COLLABORATION } \\
\hline & STEP 1 & STEP 2 & STEP 3 (A) & STEP 3 (B) & STEP 1 & STEP 2 & STEP 3 (A) & STEP 3 (B) \\
\hline Control Variables: & & & & & & & & \\
\hline Firm Size & .02 & -.08 & -.18 & -.20 & $.16^{*}$ & .07 & -.07 & -.10 \\
\hline Process Food Industry & -.05 & -.12 & -.09 & -.11 & .01 & -.04 & .02 & -.01 \\
\hline Beverage Industry & -.09 & -.07 & -.05 & -.11 & -.10 & -.11 & -.06 & -.15 \\
\hline Meat Industry & -.03 & -.00 & .00 & -.03 & -.11 & -.09 & -.08 & -.13 \\
\hline Dairy Industry & -.02 & -.01 & -.04 & -.06 & .05 & -.01 & .00 & -.03 \\
\hline Direct Effects: & & & & & & & & \\
\hline Waste Reduction & & $.46 * * *$ & $.32 * * *$ & $.29 * * *$ & & $.34 * * *$ & .02 & -.01 \\
\hline Mediating Effects: & & & & & & & & \\
\hline Environmental Integration & & & $.36 * * *$ & & & & $.60 * * *$ & \\
\hline Environmental Learning & & & & $.42 * * *$ & & & & $.66 * * *$ \\
\hline (Constant) & $4.14 * * *$ & $5.33 * * *$ & $5.72 * * *$ & $5.90 * * *$ & $2.68 * * *$ & $3.27 * * *$ & $4.05 * * *$ & $4.35^{* * *}$ \\
\hline$\Delta \mathrm{R}^{2}$ & .01 & .20 & .09 & .12 & .06 & .10 & .21 & .26 \\
\hline$\Delta \mathrm{F}$ & .23 & $35.20 * * *$ & $17.91 * * *$ & $24.64 * * *$ & 1.67 & $17.29 * * *$ & $47.96 * * *$ & $63.00 * * *$ \\
\hline Overall $\mathrm{R}^{2}$ & .01 & .21 & .30 & .32 & .06 & .16 & .37 & .42 \\
\hline Adjusted $\mathrm{R}^{2}$ & -.03 & .17 & .26 & .29 & .02 & .12 & .34 & .39 \\
\hline Overall model F & .23 & $6.11 * * *$ & $8.41 * * *$ & $9.62 * * *$ & 1.67 & $4.43 * * *$ & $11.91 * * *$ & $14.46^{* * *}$ \\
\hline $\mathrm{N}$ & 149 & 149 & 149 & 149 & 149 & 149 & 149 & 149 \\
\hline
\end{tabular}

Note. ${ }^{* * *} \mathrm{p}<0.001,{ }^{* *} \mathrm{p}<.05,{ }^{*} \mathrm{p}<.10,{ }^{\wedge} \mathrm{p}<.10$ (one-tailed tests for hypotheses; two-tailed tests for controls; standard errors in parenthesis). Standardized regression coefficients are shown. 
Hypotheses 3 and 4 assess the mediating influence of environmental integration and learning on the relationship between pollution prevention and process stewardship. The results for the mediation analyses are displayed in steps $3 \mathrm{a}$ and $3 \mathrm{~b}$ in Tables 2 and 3 . Three conditions are required for mediation to exist; (1) the independent variable must affect the mediator; (2) the independent variable must affect the dependent variable and; (3) the mediator must affect the dependent variable (Baron and Kenny, 1986). The results for hypotheses 1 and 2 indicate that condition 1 is satisfied. The results displayed in step 2 of Tables 2 and 3 indicate that condition 2 is also satisfied in all cases. Inclusion of integration as a mediator in Table 2 generates a significant increase in variance explained in the case of both supplier collaboration $\left(R^{2}=.07 ; \mathrm{p}\right.$ $<0.001)$ and customer collaboration $\left(R^{2}=.15 ; \mathrm{p}<0.001\right)$. The strong and highly significant correlation coefficients ( $\beta=.38, p<.001$ and $\beta=.57, p<.001$ respectively) indicate that condition 3 for mediation is satisfied. Further, the direct effect of the independent variable on the dependent variable becomes non-significant in both models, providing support for full mediation. In accordance with guidelines from Preacher and Hayes (2004), Sobel's test for mediation was conducted to further confirm any mediating affects identified within the analyses. The positive and highly significant result from the Sobel test $(3.10, p<.001)$, provides further support for a fully mediated relationship. Inclusion of learning as the mediating variable generates similar results in the case of both outcome variables $\left(R^{2}=.11 ; \mathrm{p}<0.001\right)$ and $\left(R^{2}=.20\right.$; $\mathrm{p}<0.001)$ respectively. Again, the correlation coefficient for the mediator is strong and statistically significant across both models ( $\beta=.46, p<.001$ and $\beta=.62, p<.001$ respectively), whilst the effect of the independent variable becomes non-significant, providing support for full mediation. The positive and highly significant Sobel test result $(2.34, p<.01)$ further supports this mediation. Taken together, these results suggest that integration and learning mediate the relationship between energy consumption reduction and process stewardship, consistent with hypotheses 3 and 4. 
Steps $3 a$ and $3 b$ in Table 2 outline the mediation results where waste reduction constitutes the independent variable. Inclusion of integration as a mediator in Table 1 generates a significant increase in variance explained in the case of both supplier collaboration $\left(R^{2}=.09 ; \mathrm{p}<0.001\right)$ and customer collaboration $\left(R^{2}=.21 ; \mathrm{p}<0.001\right)$. The strong and highly significant correlation coefficients ( $\beta=.36, p<.001$ and $\beta=.60, p<.001$ respectively) indicate that condition 3 for mediation is satisfied. The positive and significant Sobel test results $(3.53, p<.001$ and 2.60, $p<.01$ respectively) further confirm this. However, where supplier collaboration constitutes the outcome variable, the direct effect of waste reduction is reduced but remains strong and statistically significant, suggesting that partial, rather than full mediation is achieved in this case. There is evidence for full mediation where customer collaboration constitutes the outcome as the influence of waste reduction becomes non-significant in step 3a of this model. These results are echoed upon the inclusion of learning as the mediating variable (step $3 \mathrm{~b}$ in Table 2). The significance of both models is evident in the increase in variance explained $\left(R^{2}=.09 ; \mathrm{p}<0.001\right.$ and $R^{2}=.21 ; \mathrm{p}<0.001$ respectively). Further, the highly significant correlation coefficients ( $\beta=.42, p<.001$ and $\beta=.66, p<.001$ respectively) suggest that mediation exists. The positive and significant Sobel test scores $(3.53, p<.001$ and $2.70, p<.01$ respectively) further confirm that full mediation exists in these cases. Again, in the case of supplier collaboration, this mediation appears to be partial as the influence of waste reduction is reduced, yet remains statistically significant. In the case of customer collaboration, the results support a fully mediated relationship as the influence of waste reduction becomes nonsignificant upon inclusion of the mediator. Thus, hypotheses 3 and 4 are broadly supported by the results. 


\section{Discussion}

Considered together, the results suggest that implementation of internal environmental practices enables companies to develop environmental capabilities (integration and learning) that are conducive to the implementation of more advanced practices at the supply chain level. These capabilities play a mediating role in the progression from internal environmental practices to more advanced supply chain practices. Strong support for these mediating effects was obtained in support of the relationship between energy consumption reduction and both dimensions of process stewardship (supplier and customer collaboration). However, results for these mediating effects in the relationship between waste reduction and process stewardship only suggest full mediation where customer collaboration constitutes the outcome. Partial mediation is supported in the case where supplier collaboration constitutes the outcome. This partial meditation suggests that in addition to having a significant direct effect, waste reduction contributes to supplier collaboration through environmental integration and learning. While the relationship between waste reduction and supplier collaboration doesn't necessarily depend on the development of environmental capabilities, there is some evidence to suggest that these capabilities do play a role in the relationship between these two environmental practices.

A number of recent studies considering the implementation of supply chain practices find that mediating or moderating effects may vary for different outcome variables (Gallear et al., 2014; Marshall et al., 2015; Jacobs et al., 2016). The power dynamics within food supply chain relationships may be a contributing factor in understanding the differences in the pathways to working collaboratively with different actors in the supply chain to tackle environmental concerns. As the more powerful entities, retailer customers may encourage their suppliers to implement and integrate environmental efforts within their processes in order to reduce the 
environmental impact of their supply chain (Hingley, 2005). Thus, these practices may act more strongly as antecedents on the pathway towards environmental collaboration with customers. Retailers downstream in food supply chains, are facing increasing levels of pressure from a range of different stakeholders to measure and assess the environmental impact of their supply chains (Mahalik and Nambiar 2010; Yakovleva et al., 2012). As a result of these pressures, proactive companies increasingly pursue environmental collaboration with their suppliers in order to improve the environmental performance of their supply chains (Formentini and Taticchi, 2016). The results from this study provide empirical support for the existence of environmental collaboration between food manufacturing companies and their retail customers within the context of the UK food industry.

Empirical support is also provided for environmental collaboration between food manufacturing companies and their suppliers, indicating that environmental efforts do not stop with the manufacturers but are extended further upstream. The results for collaboration with suppliers were slightly weaker than for customer collaboration. Again, this may be a result of the power imbalance inherent in food supply chains (Hingley, 2005). Food manufacturers might work more closely with their customers, due to their relative power and influence. With regard to the partially mediated relationship between waste reduction, environmental capabilities and supplier collaboration, the industry context may again shed some light. This unexpected finding implies that the development of internal environmental capabilities is not essential in moving towards a collaborative approach with suppliers from internal waste reduction. In the context of the food industry companies may seek to extend their waste reduction efforts to upstream suppliers because of the potential cost benefits. The majority of companies in the food industry compete on cost and operate on very low profit margins (Roth et al., 2008; Piramuthu et al., 2013). More effective waste management can generate cost 
improvements for companies and if potential improvements can be extended upstream, it may lead to further cost improvements for food companies (Bowen et al., 2001; Graham and Potter, 2015). Both energy and waste reduction are key pollution-related concerns within the UK food industry, yet each will be addressed in different ways (DEFRA, 2017; FDF, 2017). The former relates to something that is intangible while the latter relates to something tangible and physical (Kocabasoglu et al., 2007). Thus, the internal capabilities required for firms to build upon these practices may differ. Further, packaging is a key environmental challenge within the food industry that companies have been pressured to respond to. Within the UK, government funded initiatives such as WRAP have been established to work with companies in order to tackle a variety of waste related challenges including reducing packaging and food waste (WRAP, 2017). Packaging is required to keep food products fresh and safe for consumption, yet there have been criticisms over excessive levels of packaging and the waste that results from this. Companies may work with suppliers to address this waste related concern and seek to develop more environmentally friendly packaging solutions (Preuss, 2005). Thus, this might be an area where they work with suppliers directly and draw on advice and support from third parties such as WRAP, rather than depending on their own internal environmental capabilities for support.

In spite of the many challenges facing the food industry context, the results from this study support the existence of collaborative environmental efforts both upstream and downstream within the UK food supply chain. This is consistent with other recent studies that suggest that a practical response to environmental and social sustainability concerns can be integrated at all stages of the supply chain where companies express a proactive commitment to tackling them, even despite cost pressures in certain industries (Marshall et al., 2015; Formentini and Taticchi, 2016). 


\section{Theoretical implications}

A theoretical model grounded within the NRBV and dynamic capabilities perspective was developed to assess both direct and mediating effects in the progression from a proactive pollution prevention strategy to a process stewardship strategy. The empirical results provide strong support for a direct relationship between pollution prevention and environmental capabilities suggesting that companies go through an important process of integration and learning in the implementation of internal environmental practices. The results further suggest that these integration and learning capabilities play a mediating role in the implementation of more advanced environmental practices at the supply chain level. These results provide preliminary support for recent developments in the NRBV suggesting that environmental strategies can be considered as dynamic capabilities (Aragón-Correa and López, 2007; Hart and Dowell, 2011). As companies implement these strategies internally, they will develop integration and learning capabilities that enable them to implement more advanced strategies at the supply chain level. These results are consistent with a number of studies identifying a direct relationship between internal and supply chain environmental practices (De Giovanni, 2012; Green et al., 2012; Zhu et al., 2012), yet novel in that the resources and capabilities that facilitate this progression are identified. Recent studies have called for more studies to consider 'how' companies are moving towards more advanced practices (Gallear et al., 2014; Jacobs et al., 2016). Thus, the presence of mediating factors as considered in this study is an important consideration for research.

A number of studies have started to highlight the importance of the implementation process as an emerging area of research within environmental management (Zhu et al., 2012; De BurgosGiminez et al., 2014) and internal factors such as change management practices, environmental 
training and top management support have been highlighted as important in the implementation of environmental practices. While some of these studies consider the influence of internal factors on the implementation of environmental practices (Gattiker and Carter, 2010; Sarkis et al., 2010), and others on performance outcomes from environmental practices (Ronnenberg et al., 2010; Daily et al., 2012), no studies appear to consider the role of internal factors in supporting the progression from an internal environmental strategy to a supply chain level strategy. Consistent with Hart and Dowell's (2011) suggestion, this study considers the proactive environmental strategies outlined in the NRBV as dynamic capabilities requiring support from internal processes in their implementation. The results suggest that integration and learning are both important in supporting the progression from internal to supply chain level environmental strategies. This means that companies can use existing integration processes to support the implementation of environmental practices. They can also draw on the experience they have gained from initial environmental efforts in extending these efforts to the supply chain level. The important role played by integration and learning in developing proactive environmental strategies has been highlighted conceptually within the literature (Hart, 1995; Pagell and Wu, 2009). This study confirms the import of these internal factors by generating empirical support for their role in the implementation process.

At the supply chain level, it is evident that companies are pursuing a collaborative approach with appropriate supply chain actors. This builds upon the work of Matopoulos et al (2007) who consider the role of supply chain collaboration in the context of the agri-food industry. They identify a number of benefits that can be obtained through collaboration in food supply chains. Other studies note the potential for environmental supply chain collaboration to generate a number of benefits for companies (Vachon and Klassen, 2008). The findings from this study further support these works by providing empirical support for the pursuit of 
collaborative environmental approaches among food manufacturing companies in the UK, suggesting that supply chain collaboration is an important mechanism for tackling environmental concerns within this context.

These findings may also have wider implications for environmental management research as greater understanding of the implementation process could lead to greater understanding of performance outcomes from environmental efforts. Empirical findings to date largely suggest that some environmental practices may have a positive influence on different dimensions of performance, whilst others may not (Jacobs et al., 2010; Wong et al., 2012; Graham and Potter, 2015; Tachizawa et al., 2015). The reasons behind this ambiguity have not been clear and it has been suggested that some practices may generate more benefits than others. In seeking to understand how companies implement environmental practices, we may be able to identify factors that support or facilitate success. Do companies that use internal support processes generate more positive outcomes than companies that don't? These findings stir up such questions which may help to steer future research in important directions.

\section{Managerial implications}

The findings also generate important implications for organisations and managers. Environmental pressures are not subsiding and companies cannot afford to ignore these concerns (Sarkis et al., 2010; Tognetti et al., 2015). Companies are under increasing levels of pressure to manage not only their own environmental impact, but also that of their supply chain

(Parmigiani et al., 2011; Zhu et al., 2012; Gualandris et al., 2015; Wilhelm et al., 2016). The food industry faces a number of unique environmental challenges in relation to energy emission and waste generated throughout their supply chains and companies are coming under 
increasing pressure and scrutiny to address these issues (FDF, 2017). Within this low profit margin, highly competitive environment, companies cannot afford to waste money on environmental initiatives that will be ineffective. Therefore, it is important for companies to develop a good understanding of what works well in practice and respond to the challenges that are most pressing to them. Large retailers have come under pressure in recent years to provide more information on the labelling of their products regarding their carbon footprint of the supply chain process. This inevitably places pressure on a number of food producing companies that supply their products to be more environmentally responsible. The findings from this study offer some important insights for managers into how they can implement environmental strategies at the supply chain level. It is evident that energy and waste are key issues for companies in this context and that dealing with these challenges internally is an important first step in the progression towards more advanced practices at the supply chain level. The environmental capabilities developed through internal environmental efforts are helpful in building on these efforts and developing more advanced solutions.

Through using existing mechanisms and processes for integration, environmental efforts can be communicated effectively throughout the organisation facilitating the development and implementation of new strategies and practices. Environmental integration enables the alignment of environmental strategies across different business functions and ensures that everyone is working towards the same goals. In order to support the progression to environmental strategies at the supply chain level, it is important for managers to ensure that these efforts are communicated across the company and that everyone is on board with any changes. Further, managers should draw on any experience and learning gained through prior environmental efforts to aid the implementation of supply chain strategies. Learning and experience will enable managers to identify what has worked well previously and avoid 
anything that hasn't worked well. This can facilitate effective implementation of new environmental strategies and practices. Overall, the implementation of proactive environmental strategies will be a steep learning curve for all managers and they can develop and build on this experience progressively.

\section{Conclusion}

The purpose of this study was to consider the practical implementation of proactive environmental strategies and specifically, the progression from an internally orientated environmental strategy to a supply chain level environmental strategy, using the NRBV and dynamic capabilities perspective as theoretical lenses. The results contribute to an emerging area within environmental management research that highlights the importance of understanding the implementation process in developing proactive environmental strategies (Gattiker and Carter, 2010; Hart and Dowell, 2011; Zhu et al., 2012). The first research question assessed the link between pollution prevention and the development of environmental capabilities (integration and learning). The second question considered the mediating influence of these capabilities in the development of more advanced environmental strategies at the supply chain level. Overall, the results provide broad support for the theoretical framework outlined at the start of the article.

\section{Limitations and future research directions}

The focus on a single-industry context may be viewed as a limitation as it reduces the generalisability of the results to the other industries (Marshall et al., 2015). However, it can also be argued that there are benefits associated with focus on a single industry, such as the 
ability to identify context specific environmental challenges and concerns (Darkow et al., 2015). Further, the focus on the UK as the region for data collection may also be viewed as a limitation as it limits the context of the study to one area. Again, there can be benefits to doing this, such as reduction of regulatory differences and variations in pressure that might affect the data (Sarkis et al., 2010; Marshall et al., 2015). Another important limitation to acknowledge relates to the cross-sectional nature of the data which does not allow the length of time that the practices assessed have been implemented to be accounted for. The paper seeks to understand the progression from internal environmental strategies to more advanced supply chain strategies, yet, the static nature of cross-sectional research hinders the ability to do so. While, antecedent factors can be identified in accordance with the arguments of the NRBV and dynamic capabilities perspective, the study is limited in going beyond this to understand progression. It would be interesting to explore how long the internal practices have been implemented in comparison to the supply chain practices. Timing of implementation may be an interesting avenue for future research as it would give managers an idea of the length of time it takes to develop the internal capabilities before building upon and extending them to the supply chain level.

There are a number of other potential research avenues that future studies might take in response to this study. Firstly, the counterintuitive results in relation to the antecedents of supplier collaboration practices provide an interesting avenue for future research. Future studies should seek to understand the different antecedents to environmental practices implemented at different stages of the supply chain. Further, a number of supporting factors for the implementation of environmental strategies still need to be identified and explored (Zhu et al., 2012). Application of a broader organisational learning perspective may shed further light on how companies use the experience and learning developed through existing practices 
in progressing towards more advanced practices (Argote and Miron-Spektor, 2011). Further, it would be interesting to consider the potential influence of external factors as well. For example, if a company's customer is pressuring them to be more environmentally proactive, are they offering any support in order to help them? Are companies drawing on the knowledge and skills of third parties in becoming more environmentally proactive and seeking guidance in the implementation of their environmental strategies?

\section{Acknowledgements}

This work was supported by the Department for Education \& Learning (DEL), Northern

Ireland, through its "Strengthening the all-Island Research Base" initiative.

\section{Appendices}

\section{Appendix 1a- Factor Loadings (Group 1)}

\begin{tabular}{l|c|c}
\hline \multicolumn{1}{c|}{ Items } & $\mathbf{1}$ & $\mathbf{2}$ \\
\hline Environmental Integration & .82 & \\
We have frequent face-to-face communication about environmental issues across & & \\
departments & .87 & \\
We actively share knowledge across internal functions in order to minimise our plant's & & \\
environmental impact & & \\
We actively cooperate across internal functions in order to minimise our plant's & & \\
environmental impact & & .80 \\
Supplier Collaboration & .87 \\
We cooperate with our suppliers to improve their waste reduction initiatives & .94 \\
We cooperate with our suppliers for cleaner production & .88 \\
We encourage our suppliers to be more efficient in cutting back waste & \\
We cooperate with our suppliers to achieve environmental objectives & \\
Energy consumption reduction & \\
We have taken steps to reduce use of excess energy & .77 \\
We have assessed operations to identify areas of energy inefficiency & .83 \\
We have communicated with employees regarding energy consumption & .84 \\
We monitor energy use to see where improvements can be made & .78 \\
Our employees have been trained in reducing energy consumption & & .89 \\
\hline & & \\
\hline
\end{tabular}

\section{Appendix 1b - Factor loadings (Group 2)}

\begin{tabular}{|c|c|c|c|}
\hline Items & 1 & 2 & 3 \\
\hline $\begin{array}{l}\text { Waste Reduction } \\
\text { We monitor and assess levels of waste to see where improvements can be made }\end{array}$ & .83 & & \\
\hline
\end{tabular}




\begin{tabular}{|c|c|c|c|}
\hline We have communicated with employees regarding waste reduction & .84 & & \\
\hline We are striving to eliminate unnecessary waste from our production process & .53 & & \\
\hline We train our employees to effectively reduce waste & .87 & & \\
\hline We recycle waste materials where possible & .81 & & \\
\hline $\begin{array}{l}\text { We have sought help from third parties in dealing with waste reduction } \\
\text { Environmental Learning }\end{array}$ & .70 & & \\
\hline Our plant possesses a great deal of environmental knowledge & & .76 & \\
\hline Our plant possesses pollution prevention skills & & 80 & \\
\hline Our plant has strong expertise with the latest environmental technologies & & .79 & \\
\hline $\begin{array}{l}\text { Our plant has a high level of environmental expertise compared with our industry } \\
\text { Customer Collaboration }\end{array}$ & & .72 & \\
\hline Working together to reduce the environmental impact of our activities & & & .83 \\
\hline $\begin{array}{l}\text { Making joint decisions about ways to reduce the overall environmental impact of our } \\
\text { products }\end{array}$ & & & .85 \\
\hline Conducting joint planning to anticipate and resolve environmental-related problems & & & .89 \\
\hline $\begin{array}{l}\text { Developing a mutual understanding of responsibilities regarding environmental } \\
\text { performance }\end{array}$ & & & .85 \\
\hline Achieving environmental goals collectively & & & .85 \\
\hline $\begin{array}{r}\text { Variance Explained } \\
\text { Eigenvalues } \\
\end{array}$ & $\begin{array}{c}50.99 \\
7.65 \\
\end{array}$ & $\begin{array}{l}16.68 \\
2.50\end{array}$ & $\begin{array}{l}7.50 \\
1.12 \\
\end{array}$ \\
\hline
\end{tabular}

\section{References}

Abou-Elela, S., Nasr, F., Ibrahim, H., Badr, N. and Askalany, A. (2008). Pollution prevention pays off in a board paper mill, Journal of Cleaner Production, 16: 330-334.

Accorsi, R., Cascini, A., Cholette, S. and Manzini, R. (2014). Economic and environmental assessment of reusable plastic containers: A food catering supply chain case study. International Journal of Production Economics, 152: 88-101.

Agustina, D., C. Lee and R. Piplani (2014). Vehicle scheduling and routing at a cross docking center for food supply chains, International Journal of Production Economics, 152: 29-41.

Ambrosini, V. and Bowman, C. (2009). What are dynamic capabilities and are they a useful construct in strategic management? International Journal of Management Reviews, 11 (1): 29-49.

Akin-Ates, M., J. Bloemhof, E. Raaij and F. Wynstra (2012). Proactive environmental strategy in a supply chain context: the mediating role of investments. International Journal of Production Research, 50 (4): 1079-1095.

Aragón-Correa, J. A. and E. A. Rubio-López (2007). Proactive Corporate Environmental Strategies: Myths and Misunderstandings. Long Range Planning, 40(3): 357-381.

Argote, L. and E. Miron-Spektor (2011). Organizational learning: From experience to knowledge.

Organization Science, 22 (5): 1123-1137. 
Armstrong, S. J. and T. S. Overton (1977). Estimating non-response bias in mail surveys. Journal of Marketing Research, 14(August): 396-402.

Awaysheh, A. and Klassen, R.D. (2010). The impact of supply chain structure on the use of supplier socially responsible practices, International Journal of Operations \& Production Management, 30 (12): 1246-1268.

Barney, J. (1991). Firm resources and sustained competitive advantage. Journal of Management, 17(1): 99120.

Baron, R. and Kenny, D. (1986). The moderator-mediator variable distinction in social psychological research: Conceptual, strategic and statistical considerations. Journal of Personality and Social Psychology, 51 (6): 1173-1182.

Belayuthum, S., V. Gonzalez and T. Wing Yiu (2016). A cleaner production-pollution prevention based framework for construction site induced water pollution. Journal of Cleaner Production, 135: 13631378.

Bhupendra, K. and S. Sangle (2016). Pollution prevention strategy: a study of Indian firms. Journal of Cleaner Production, 133: 795-802.

Blome, C., A. Paulraj and K. Schuetz (2014). Supply chain collaboration and sustainability: a profile deviation analysis. International Journal of Operations and Production Management, 34 (5): 639663.

Chen, I. and Paulraj, A. (2004). Towards a theory of supply chain management: the constructs and measurements. Journal of Operations Management, 22(2): 119-150.

Christmann, P. (2000). Effects of "best practices" of environmental management on cost advantage: the role of complementary assets. Academy of Management Journal, 43(4): 663-680.

Daily, B., Bishop, J. and Massoud, J. (2012). The role of training and empowerment in environmental performance. International Journal of Operations and Production Management, 32 (5): 631-647.

Darkow, I., B. Foerster and H. von der Gracht. (2015). Sustainability in food service supply chains: future expectations from European industry experts toward the environmental perspective. Supply Chain Management: An International Journal, 20 (2): 163-178.

Darnall, N., I. Henriques and P. Sadorsky (2010). Adopting Proactive Environmental Strategy: The influence of stakeholders and firm size. Journal of Management Studies, 47(6): 1072-1094. 
De Burgos-Jiminez, J., Vazquez-Brust, D. and Plaza-Ubeda, J. (2014). Environmental protection and financial performance: an empirical analysis in Wales, International Journal of Production and Operations Management, 33 (8): 981-1018.

DEFRA (2017) Department for Environment, Food and Rural Affairs, http://www.defra.gov.uk/ , accessed $29 / 5 / 2017$

Dillman, D. (2007). Mail and Internet Surveys: The Tailored Design Method. New Jersey, John Wiley and Sons Inc.

Drucker, D. (2005). Doing Research: Methods of Inquiry for Conflict Analysis. California, Sage Publications.

Eisenhardt, K. and Martin, J. (2000). Dynamic capabilities: what are they? Strategic Management Journal, 21 (10-11): 1105-1121.

Field, A. (2009). Discovering statistics using SPSS. London, Sage Publications.

FDF (2017), Food and Drink Federation, http://www.fdf.org.uk/ , accessed 29/05/2017

Foerstl, K., Hartmann, E., Wynstra, F. and Moser, R. (2013). Cross-functional integration and functional coordination in purchasing and supply management: Antecedents and effects on purchasing and firm performance, International Journal of Operations and Production Management, 33 (6): 689721.

Formentini, M. and P. Taticchi (2016). Corporate sustainability approaches and governance mechanisms in sustainable supply chain management. Journal of Cleaner Production, 112: 1920-1933.

Forza, C. (2002). Survey research in operations management: a process-based perspective. International Journal of Operations \& Production Management, 22(2): 152-194.

Gattiker, T. and C. Carter. (2010). Understanding project champions' ability to gain intra-organizational commitment for environmental projects. Journal of Operations Management, 28: 72-85.

Graham, S. and A. Potter (2015). Environmental operations management and its links with proactivity and performance: A study of the UK food industry. International Journal of Production Economics, 170: $146-159$.

Green, K. W., Zelbst, P. J., Bhadauria, V. and Meacham, J. (2012). Do environmental collaboration and monitoring enhance organisational performance? Industrial Management and Data systems, 112(2): 186-205.

Greene, W. H. (2011). Econometric Analysis. Pearson Education, Harlow, England. 
Grekova, K., H. Bremmers, J. Trienekens, R. Kemp and S. Omta (2014). Extending environmental management beyond the firm boundaries: An empirical study of Dutch food and beverage firms. International Journal of Production Economics, 152: 174-187.

Grimm, J., J. Hofstetter and J. Sarkis. (2014). Critical factors for sub-supplier management: A sustainable food supply chains perspective. International Journal of Production Economics, 152: 159-173.

Grosvold, J., S. Hoejmose and J. Roehrich. (2014). Squaring the circle. Supply Chain Management: An International Journal, 19 (3): 292-305.

Gualandris, J., R. Klassen, S. Vachon and M. Kalchschmidt. (2015). Sustainable evaluation and verification in supply chains: Aligning and leveraging accountability to stakeholders. Journal of Operations Management, 38: 1-13.

Hair, J. F., Black, W. C., Babin, B., Anderson, R. and Tatham, R. (2006). Multivariate Data Analysis, Pearson Prentice Hall.

Hart, S. and Dowell, G. (2011). A natural-resource-based view of the firm: Fifteen years after. Journal of Management, 37 (5): 1464-1479.

Hart, S. (1995). A natural-resource-based view of the firm. Academy of Management Review, 20(4): 9861014.

Hawkins, T. R., Singh, B., Majeau-Bettez, G. and Strømman, A. H. (2013), Comparative Environmental Life Cycle Assessment of Conventional and Electric Vehicles. Journal of Industrial Ecology, 17: 53-64. Hingley, M. (2004). Relationship development in the UK fresh produce supply chain. Journal of Marketing Channels, 12 (1): 27-50.

Hingley, M., A. Lindgreen and D. Grant (2015). Intermediaries in power-laden retail supply chains: An opportunity to improve buyer-supplier relationships and collaboration. Industrial Marketing Management, 50: 78-84.

Hingley, M. (2005). Power to all our friends? Living with imbalance in supplier-retailer relationships. Industrial Marketing Management, 34: 848-858.

Hoejmose, S., J. Grosvold and A. Millington (2013). Socially responsible supply chains: power asymmetries and joint dependence. Supply Chain Management: An International Journal, 18 (3): 277-291.

Hofer, C., D. Cantor and J. Dai (2012). The competitive determinants of a firm's environmental management activities: Evidence from US manufacturing industries. Journal of Operations Management, 30: 6984. 
Hoque, A. and A. Clarke (2013). Greening of industries in Bangladesh: pollution prevention practices. Journal of Cleaner Production, 51: 47-56.

Jacobs, M., W. Yu and R. Chavez (2016). The effect of internal communication and employee satisfaction on supply chain integration. International Journal of Production Economics, 171: 60-70.

Jacobs, B., V. Singhal and R. Subramanian (2010). An empirical investigation of environmental performance and the market value of the firm. Journal of Operations Management, 28: 430-441.

Klassen, R. (2000). Exploring the linkage between investment in manufacturing and environmental technologies. International Journal of Operations and Production Management, 20 (2): 127-147.

Kiron, D., N. Kruschwitz, K. Haanaes and I. Streng Velken (2012). Sustainability Nears a Tipping Point. MIT Management Sloan Review, 53(2): 68-74.

Kocabasoglu, C., C. Prahinski and R. Klassen (2007). Linking forward and reverse supply chain investments: The role of business uncertainty. Journal of Operations Management, 25: 1141-1160.

Kumar, S., Teichman, S., Timpernagel. T. (2012). A green supply chain is a requirement for profitability. International Journal of Production Research 50 (5): 1278-1296.

Lee, S. (2015). The effects of green supply chain management on the supplier's performance through social capital accumulation. Supply Chain Management: An International Journal, 20 (1): 42-55.

Lee, K., B. Min and K. Yook. (2015). The impacts of carbon emissions and environmental research and development investment on firm performance. International Journal of Production Economics, 167: $1-11$.

López-Gamero, M., Molina-Azorin, J. and Claver-Cortes, E. (2009). The whole relationship between environmental variables and firm performance: Competitive advantage and firm resources as mediator variables, Journal of Environmental Management, 90: 3110-3121.

Li, D., Wang, X., Chan, H. and Manzini, R. (2014). Editorial: Sustainable food supply chain management. International Journal of Production Economics, 152: 1-8.

Maloni, M. and Brown, M. (2006). Corporate social responsibility in the supply chain: An application in the food industry. Journal of Business Ethics, 68: 35-52.

Mahalik, N. and A. Nambiar. 2010. "Trends in food packaging and manufacturing systems and technology." Trends in Food Science and Technology 21: 117-128. 
Marshall, D., L. McCarthy, P. McGrath and M. Claudy. (2015). Going above and beyond: how sustainability culture and entrepreneurial orientation drive social sustainability supply chain practice adoption. Supply Chain Management: An International Journal, 20 (4): 434-454.

Matopoulous, A., M. Vlachopoulou, V. Manthou and B. Manos (2007). A conceptual framework for supply chain collaboration: empirical evidence from the agri-food industry. Supply Chain Management: An International Journal, 12 (3): 177-186.

Mattas, K. and E. Tsakiridou (2010). Shedding fresh light on food industry's role: the recession's aftermath. Trends in Food Science and Technology, 21: 212-216.

Mejías, A., E. Paz and J. Pardo. (2016). Efficiency and sustainability through the best practices in the Logistics Social Responsibility framework. International Journal of Operations and Production Management, 36 (2): 164-199.

Mena, C., L. Terry, A. Williams and L. Ellram (2014). Causes of waste across multi-tier networks: Cases in the UK food sector. International Journal of Production Economics, 152: 144-158.

Michalisin, M. D. and B. T. Stinchfield (2010). Climate Change Strategies and Firm Performance: An Empirical Investigation of the Natural Resource- Based View of the Firm. Journal of Business Strategies, 27(2): 123-149.

Montabon, F., R. Sroufe and R. Narashimhan (2007). An examination of corporate reporting, environmental management practices and firm performance. Journal of Operations Management, 25: 998-1014.

New, S. (2015). Modern slavery and the supply chain: the limits of corporate social responsibility? Supply Chain Management: An International Journal, 20 (6): 697-707.

Pagell, M. (2004). Understanding the factors that enable and inhibit the integration of operations, purchasing and logistics. Journal of Operations Management, 22(5): 459-487.

Pagell, M. and Z. Wu (2009). Building a more complete theory of sustainable supply chain management using case studies of 10 exemplars. Journal of Supply Chain Management, 45(2): 37-56.

Pagell, M. and Gobeli, D. (2009), How plant managers' experiences and attitudes toward sustainability relate to operational performance, Production and Operations Management, Vol. 8 No. 3, pp. 278-299.

Parmigiani, A., R. Klassen and M. Russo (2011). Efficiency meets accountability: Performance implications of supply chain configuration, control and capabilities. Journal of Operations Management, 29: 212-223. 
Paulraj, A. (2011). Understanding the relationships between internal resources and capabilities, sustainable supply management and organisational sustainability. Journal of Supply Chain Management,_47(1): $19-37$.

Paulraj, A. (2008). Environmental motivations: a classification scheme and its impact on environmental strategies. Business Strategy and the Environment.

Preacher, K. and Hayes, A. (2004). SPSS and SAS procedures for estimating indirect effects in simple mediation models. Behaviour research methods, Instruments \& Computers, 36 (4): 717-731.

Pullman, M., Maloni, M. and Carter, C. (2009). Food for thought: social versus environmental sustainability practices and performance outcomes. Journal of Supply Chain Management, 45(4): 38-54.

Ronnenberg, S., M. Graham and F. Mahmoodi (2011). The important role of change management in environmental management system implementation. International Journal of Operations and Production Management, 31 (6): 631-647.

Sarkis, J., P. Gonzalez-Torre and B. Adenso-Dias (2010). Stakeholder pressure and the adoption of environmental practices: The mediating effect of training. Journal of Operations Management, 28: 163-176.

Schoenherr, T. (2012). The role of environmental management in sustainable business development: A multi-country investigation. International Journal of Production Economics, 140: 116-128.

Schreyogg, G. and Kliesch-Eberl, M. (2007). How dynamic can organisational capabilities be? Strategic Management Journal, 28 (9): 913-933.

Shukla, M. and S. Jharkharia (2013). Agri-fresh produce supply chain management: a state-of-the-art literature review. International Journal of Operations and Production Management, 33(2): 114258.

Tachizawa, E., C. Giminez and V. Sierra. (2015). Green supply chain management approaches: drivers and performance implications. International Journal of Operation and Production Management, 35 (11): 1546-1566.

Tashman, P. and Marano, V. (2009). Dynamic capabilities and base of the pyramid strategies. Journal of Business Ethics, 89 (4): 495-514.

Tate, W., L. M. Ellram and J. Kirchoff (2010). Corporate social responsibility reports: A thematic analysis related to supply chain management. Journal of Supply Chain Management, 46 (1): 19.

Teece, D. (2009). Dynamic Capabilities and Strategic Management: Organising for innovation and growth, Oxford University Press. 
Teece, D., G. Pisano and Shuen, A. (1997). Dynamic capabilities and strategic management. Strategic Management Journal, 18(7): 509-533.

Thoumy, M. and Vachon, S. (2012). Environmental projects and financial performance: Exploring the impact of project characteristics. International Journal of Production Economics, 140: 28-34.

Tognetti, A., P. Grosse-Ruyken and S. Wagner. (2015). Green supply chain network optimization and the trade-off between environmental and economic objectives. International Journal of Production Economics, 170: 385-392.

Trentin, A., C. Forza and E. Perin. (2015). Embeddedness and path dependence of organizational capabilities for mass customization and green management: A longitudinal case study in the machinery industry. International Journal of Production Economics, 169: 253-276.

Vachon, S. and Klassen, R. (2008). Environmental management and manufacturing performance: The role of collaboration in the supply chain. International Journal of Production Economics, 111: 299-315.

Vachon, S., A. Halley and M. Beaulieu (2009). Aligning competitive priorities in the supply chain: the role of interactions with suppliers. International Journal of Operations and Production Management, 29 (4): $322-340$.

Vachon, S. and R. Klassen (2006). Extending green practices across the supply chain: The impact of upstream and downstream integration. International Journal of Operations and Production Management, 26(7): 795-821.

Vanpoucke, E., A. Vereecke and M. Wetzels. (2014). Developing supplier integration capabilities for sustainable competitive advantage: A dynamic capabilities approach. Journal of Operations Management, 32: 446-461.

Walley, N., \& Whitehead, B. (1994). It's not easy being green. Harvard Business Review, May-June, 46-52.

Wiengarten, F., P. Humphreys, A. McKittrick and B. Fynes (2013). Investigating the impact of e-business applications on supply chain collaboration in the German automotive industry, International Journal of Operations and Production Management, 33 (1): 25-48.

Wilhelm, M., C. Blome, V. Bhakoo and A. Paulraj. (2016). Sustainability in multi-tier supply chains: Understanding the double agency role of the first-tier supplier. Journal of Operations Management, 41: $42-60$. 
Wong, C., K. Lai, K. Shang, C. Lu and T. Leung (2012). Green operations and the moderating role of environmental management capability of suppliers on manufacturing firm performance. International Journal of Production Economics, 140: 283-294.

WRAP (2011), Working together for a world without waste, http://www.wrap.org.uk/, accessed $29 / 07 / 2011$

Wu, Z. and M. Pagell (2011). Balancing priorities: Decision-making in sustainable supply chain management. Journal of Operations Management, 29: 577-590.

Yakovleva, N., J. Sarkis, and T. Sloan. 2012. "Sustainable benchmarking of supply chains: the case of the food industry." International Journal of Production Research 50 (5): 1297-1317.

Zhu, Q., Sarkis, J. and Lai, K. (2012). Examining the effects of green supply chain management practices and their mediators in performance improvements. International Journal of Production Research, 50(5): 1377-1394. 